\title{
INTENTIONS OF PATIENTS WITH DIABETES TO PARTICIPATE IN REGULAR PHYSICAL ACTIVITY: APPLICATION OF THE THEORY OF PLANNED BEHAVIOUR
}

\author{
Brigita Miežiené $\dot{\mathbf{1}}^{1,2}$, Liuda Šinkariova ${ }^{1}$, Rasa Jankauskiené $\dot{\mathbf{2}}^{2}$ \\ Vytautas Magnus University ${ }^{\prime}$, Kaunas, Lithuania \\ Lithuanian Sports University ${ }^{2}$, Kaunas, Lithuania
}

\begin{abstract}
Background. The aim of this study is to evaluate the predictive power of affective and cognitive attitudes, perceived behavioural control, subjective norms and past behaviour for intentions to be physically active in a sample of patients with diabetes.

Methods. The study included 114 patients with diabetes, $31.2 \%$ were men, $62.3 \%$ had Type 1 diabetes. Mean age of participants was $44.08 \pm 19.31$ years. Past physical activity behaviour was measured using physical activity scale from Summary of Diabetes Self-Care Activities (SDSCA) (Cronbach alpha .62) (Toobert, Hamsted, \& Glasgow, 2000). Variables within Theory of planet behaviour (intentions, affective and cognitive attitudes, subjective norms and perceived behavioural control) were developed based on the recommendations made by Ajzen (2006). All Theory of planet behaviour questions were scored using a 7-point Likert scale. Cronbach alphas varied from .61 to .96 .

Results. Perceived behavioural control and subjective norm were significant predictors of intentions $(p<.05)$. Emotional and cognitive attitudes as well as past physical activity were not related to intentions to exercise $(p>.05)$.

Conclusions. Enhancing self-efficacy and ability to control the disease as well as strengthening positive relationships of patients with members of the team involved in the treatment, whose attitudes are regarded, should be considered developing interventions aimed at increasing the motivation of patients with diabetes to regularly practice physical activities.
\end{abstract}

Keywords: health behaviour, motivation, theory.

\section{INTRODUCTION}

$\mathrm{S}$ cientific literature states that physical activity (PA) helps patients with diabetes to control weight, blood pressure, strengthens bones, reduces the risk of cardiovascular disease and cancer (Standards of Medical Care in Diabetes-2012, 2011); Hayashino, Jackson, Fukumori, Nakamura, \& Fukuhara, 2012). In addition, scientists, physicians, and organizations of patients with diabetes emphasize that PA is beneficial to the patients with diabetes even more than non-diabetic population as PA also helps to control sugar in the blood (Chimen et al., 2011). The American Diabetes Association (Standards of Medical Care in Diabetes-2011, 2010) recommends engaging in at least 150 minutes of moderate-intensity activity every week. So, PA is a "prescribed behaviour" for patients with diabetes.

However, despite the lot of information in the media about the benefits of PA, established guidelines for safe exercising, many patients are insufficiently physically active. Studies show that although PA level of patients with Type 1 diabetes is similar to that in the general population, the optimal health-enhancing level of physical activity is not reached (Resnick, Foster, Bardsley, \& Ratner, 2006). Even a bigger problem exists among patients 
with Type 2 diabetes. Of US adult individuals with Type 2 diabetes, $31 \%$ reported no regular PA and another 38\% reported less than recommended levels of PA. Older individuals, women, and those with low income were more likely to report no regular exercise (Nelson, Reiber, \& Boyko, 2002). On the other hand, inactive lifestyle is a modifiable risk factor.

Nevertheless, changing behaviour of a person or community is one of the most difficult challenges for health professionals. Many theories analyse the motivation for health-related behaviour. The theory is the basis for any health education methods. The theory generally outlines why people engage or do not engage in their health-care.

Looking from the perspective of fundamental science, the theory should be tested in various fields in different populations. For the intervention to be effective, in-depth understanding of behaviour is required and various aspects of behaviour should be studied in a specific population. Theories of health-behaviour change provide information about the psychosocial behavioural mechanisms and help to identify targets for intervention. Although an intervention may not affect the behaviour directly, it may affect indirectly through other psychosocial factors, such as perception or motivation. Testing the theory helps to highlight the mechanisms through which an intervention works in a specific population. Testing the theory in the different populations helps to explain why and under what circumstances an intervention is effective (e.g. intervention affects only a particular sociodemographic group) (Patrick \& Williams, 2012).

Unfortunately, executing educational programs in the institutions of health care, disease-oriented approach is the most common. Standard instructions for the patients are given and medication prescribed seeking compliance with treatment. However, various psychosocial factors are rarely taken into account. Meanwhile, diabetes control mostly depends not on medical progress but on health behaviour. Many theories have been used to understand PA behaviour. Theory of planned behaviour (TPB) is one of the most frequently used empirically tested theories applied to understand health-related physical activity behaviour in various populations (Boudreau \& Godin, 2009; Hagger et al., 2007; Martin, Oliver, \& McCaughtry, 2007).

Theory of planned behaviour. The theory posits that intentions are the proximal motivational predictors of behaviour. The intentions reflect the perceived probability that a person will perform a particular behaviour. Intentions indicate the degree a person is intended to perform certain behaviour. Intentions could be expressed only if the behaviour is under volitional control. They are assumed to include the motivational factors that influence behaviour. One of the main factors predicting intentions according to TPB is perceived behavioural control (PBC). $\mathrm{PBC}$ refers to the perception of how easy or difficult it is to perform certain behaviour and, depending on the accuracy of perceptions, might overlap or differ from actual control. PBC reflects selfefficacy and, if is realistic, then together with intentions could directly predict behaviour. Another salient construct predicting intentions is social factor - subjective norms. Subjective norms sum up the motivation to respect expectations of significant others' for personal involvement in a particular behaviour. Construct reflects the level of obedience to the norms of significant others. Finally, attitudes towards particular behaviour are a person's overall positive or negative evaluation of certain behaviour, considering its benefits and deficiencies (Ajzen, 1991). Although, TPB belongs to the group of social-cognitive theories, recently along the cognitive or instrumental attitudes (e. g. addressing behaviour as "harmful - beneficial"), also affective component of attitudes - feelings towards behaviour (e. g. addressing behaviour as "not enjoyable - enjoyable") received attention (Conner, 2013). Studies show that affective attitudes (desires) are stronger predictors of intentions than the cognitive ones (reasons) (Lawton, Conner, \& Parker, 2009). Kraft, Rise, Sutton, and Røysamb (2005) suggest that the role of affective attitudes is often underestimated in the research.

TPB also considers past behaviour as one of the predictors of intentions and future behaviour. Initially past behaviour was considered as a habit, but Ajzen (1991) stated that past behaviour in TPB should be best treated not as a measure of habit but as a reflection of all factors that define behaviour. There are reasons to think that past behaviour is an experience which acts as a basis to form positive or negative attitudes and intentions towards the specific behaviour.

The present research. Theory of planned behaviour is well known as a useful framework for studying PA behaviour in a general population. But generalizability of findings to clinical populations may be problematic and studies have shown mixed 
support of psychosocial factors within the TPB framework. Moreover, TPB has not been tested at all in diabetic population in Lithuania.

As subjective norms which represent social pressure is less prominent factor in predicting behaviour in general populations (Carter-Parker, Edwards, \& McCleary-Jones, 2012; Plotnikoff et al., 2011), it could be hypothesized that they play a rather significant role in clinical populations as position of significant others such as physicians about specific behaviour is supposed to be regarded. Although, some studies with diabetic patients found evidence supporting the relationship between subjective norms and intentions to exercise (Blue, 2007; Omondi, Walingo, Mbagaya, \& Othuon, 2010) while others failed (Boudreau \& Godin, 2009). The same incongruity could be applied to perceived behavioural control as some studies reveal $\mathrm{PBC}$ as salient predictor of intentions (Boudreau \& Godin, 2009), yet another did not indicate the association (Davies, 2008; Omondi et al., 2010). Meanwhile literature states that attitudes are the mostly evidence based factor in predicting intentions to exercise (Boudreau \& Godin, 2009; Omondi et al., 2010; Plotnikoff, Courneya, Trinh, Karunamuni, \& Sigal, 2008). Yet, up to the present examining the predictive value of attitudes to intentions in diabetic population emotional and cognitive attitudes were not distinguished. So, the present study attempts to add evidence to the existing research within the framework of TPB and to examine the psychosocial factors of physical activity behaviour taking into account both desire and reason to perform behaviour. It is expected that in diabetic population intentions to exercise would be predicted by both affective and cognitive attitudes, subjective norms, perceived behavioural control and past behaviour with the PBC as the most prominent predictor followed by the affective attitudes.

The aim of this study was to evaluate the predictive power of affective and cognitive attitudes, perceived behavioural control, subjective norms and past behaviour for intentions to be physically active in a sample of patients with diabetes.

\section{METHODS}

\section{Participants}

The study included 114 patients with diabetes, $31.2 \%$ were men, $62.3 \%$ had Type 1 diabetes. The age of participants varied from 18 to 78 years, the mean age was $44.08 \pm 19.31$ years. The study was approved by Lithuanian Ethics Committee.

\section{Procedure}

The present research was the part of a bigger study examining motivational factors of health behaviour (physical activity, diet, blood sugar testing and insulin/medication taking) in patients with diabetes. A cross-sectional study design was applied to determine the ability of the TPB to identify predictors of intentions to exercise. Questionnaires were delivered in local associations of people with diabetes in several Lithuanian cities and online, placing an invitation to participate in the study in Facebook profile of the Association of People with Diabetes.

\section{Instruments}

Past physical activity behaviour was measured using physical activity scale from Summary of Diabetes Self-Care Activities (SDSCA) measure (Toobert et al., 2000). The scale consisted of two items (On how many of the last seven days did you participate in at least 30 minutes of physical activity? (Total minutes of continuous activity, including walking) and $O n$ how many of the last seven days did you participate in a specific exercise session (such as swimming, walking, biking) other than what you do around the house or as part of your work?). Participants had to indicate the number of days from 0 to 7 on the scale. Authors of the SDSCA state that correlations with other measures of exercise generally supported the validity of the SDSCA subscales. The internal consistency of the scale in the present study is only satisfactorily (Cronbach alpha .62).

Questions within TPB were developed on the basis of the recommendations made by Ajzen (2006). All TPB questions were scored using a 7-point Likert scale.

Intentions to exercise were assessed from responses to 3-item statements (e. g. The following month I plan to be physically active 30 min every day or engage in more vigorous physical activity three times a week). Responses were given on 7-point semantic differential scales anchored by the "totally disagree - totally agree" at alternate ends of the scale. Internal consistency of the scale was very good (Cronbach alpha .96).

Attitudes were measured by question which was worded "In your opinion, to be physically active $30 \mathrm{~min}$ every day or engage in more vigorous physical activity three times a week is..." and a semantic differential scale was used to access 
attitudes toward exercise. Answers (6 items) were constructed using bipolar adjective pairs, tree of them measured affective attitude (boring - exciting, stressful - not stressful, unpleasant - fun) and another three - cognitive (bad - good, damaging health - healthful, harmful-useful). The means of every 3 items were calculated to measure affective (Cronbach alpha .75) and cognitive (Cronbach alpha .61) attitudes.

Subjective norms were measured from the four items (e.g. Most of people whose opinion I respect think I should be physically active every day for 30 min or engage in more vigorous physical activity three times a week which was evaluated on a scale using the "totally disagree - totally agree" word pair (Cronbach alpha .84).

Perceived behavioural control (PBC) was averaged from three items (e.g. I am sure that it's up to me that I can to be physically active $30 \mathrm{~min}$ every day or engage in more vigorous physical activity three times a week) and assessed participants' perception of their ability to meet the exercise criteria. PBC was evaluated on a scale using the "totally disagree - totally agree" word pair (Cronbach alpha .77).

\section{Statistical analysis}

Statistical data analysis was completed using SPSS for Windows 19.0 software (SPSS Inc., Chicago, USA). Descriptive statistics was performed to show sample characteristics. Tests of normality were done and indicators of skewness and kurtosis showed that data on each scale approached the normal distribution. Correlational analysis using Pearson coefficient was used to indicate the relationships between variables. Stepwise regression analysis was performed in order to evaluate the influence of TPB variables on intentions to exercise controlling for block of socio-demographical and clinical factors. Results were considered statistically significant when a probability value $(p)$ was less than .05 or equal.

\section{RESULTS}

Table 1 displays the sample characteristics of individuals with Type 1 (62.3\%) or Type $2(37.7 \%)$ diabetes, mostly women. The mean of glycaemic index HbAlc was higher than recommended by American diabetes association (ADA, 2010) of $<$ $7 \%$. The mean age was 44 years. Half of the sample reported that their incomes were enough for them. More than half of the sample had higher than high school education. More than two thirds of diabetes patients reported insufficient or no physical activity.

Table 1. Sample characteristics

\begin{tabular}{|c|c|}
\hline Variable & $\begin{array}{c}\text { Data } \\
(\text { mean } \pm S E \text { or \%) }\end{array}$ \\
\hline \multicolumn{2}{|l|}{ Type of diabetes } \\
\hline Type 1 & 62.3 \\
\hline Type 2 & 37.7 \\
\hline$H b A l c$ & $8.19 \pm 1.97$ \\
\hline \multicolumn{2}{|l|}{ Gender } \\
\hline Men & 31.2 \\
\hline Women & 68.8 \\
\hline Age & $44.08 \pm 9.31$ \\
\hline \multicolumn{2}{|l|}{ Education } \\
\hline High school & 45.6 \\
\hline College & 15.8 \\
\hline Higher & 38.6 \\
\hline \multicolumn{2}{|l|}{ Income } \\
\hline Not enough & 38.6 \\
\hline Enough & 53.5 \\
\hline More than enough & 7.9 \\
\hline Physical activity & $7.09 \pm 3.56$ \\
\hline Inactive & 0.9 \\
\hline Insufficient & 40.7 \\
\hline Recommended level & 58.3 \\
\hline
\end{tabular}

Correlational analysis reveals that intentions to exercise is correlated with past physical activity behaviour and every other variable included in the model of theory of planned behaviour. Perceived behavioural control and subjective norms were strongly correlated with intentions to exercise. Past PA behaviour and intentions correlated to a lesser degree. Past PA behaviour was moderately related to perceived behavioural control and weakly to both affective and cognitive attitudes, but no correlation existed between past PA behaviour and subjective norms. Affective and cognitive attitudes had weak inter-correlation.

Results in Table 3 indicate that the type of diabetes was significant predicting intentions to be physically active in the following month and showed the tendency that people with Type 1 diabetes were more inclined to exercise than Type 2 diabetes patients. However, the model was non-significant $(p=.141)$. Nevertheless, when the variables of TPB were included in Step 2, the type of diabetes became non-significant. Perceived behavioural control and subjective norm were significant predictors of intentions $(p<.05)$. Deeper analysis using stepwise method revealed that PBC accounted for $43.8 \%$ 
Table 2. Correlations between the study variables (Pearson's coefficient)

Note. ${ }^{*}-p<.05 ; * *-p<.01$.

\begin{tabular}{|c|c|c|c|c|c|}
\hline Study variables & $\begin{array}{c}\text { Affective } \\
\text { attitudes }\end{array}$ & $\begin{array}{c}\text { Cognitive } \\
\text { attitudes }\end{array}$ & $\begin{array}{c}\text { Perceived } \\
\text { behavioural } \\
\text { control }\end{array}$ & $\begin{array}{c}\text { Subjective } \\
\text { norms }\end{array}$ & Intentions \\
\hline $\begin{array}{c}\text { Past PA } \\
\text { behaviour }\end{array}$ & $.224^{*}$ & $.275^{* *}$ & $.501^{* *}$ & .143 & $.434^{* *}$ \\
\hline $\begin{array}{c}\text { Affective } \\
\text { attitudes }\end{array}$ & 1 & $.448^{* *}$ & $.337^{* *}$ & $.220^{*}$ & $.312^{* *}$ \\
\hline $\begin{array}{c}\text { Cognitive } \\
\text { attitudes }\end{array}$ & - & 1 & $.371^{* *}$ & $.215^{*}$ & $.349^{* *}$ \\
\hline $\begin{array}{c}\text { Perceived } \\
\text { behavioural } \\
\text { control }\end{array}$ & - & - & 1 & $.385^{* *}$ & $.706^{* *}$ \\
\hline $\begin{array}{c}\text { Subjective } \\
\text { norms }\end{array}$ & - & - & - & 1 & $.632^{* *}$ \\
\hline
\end{tabular}

\begin{tabular}{|l|c|c|c|c|}
\hline \multicolumn{1}{|c|}{ Variable } & Adj $\boldsymbol{R}^{2}$ & B & $\boldsymbol{t}$ & $\boldsymbol{p}$ \\
\hline Step $1 F(3)=1.843, p=.146$ & .029 & & & \\
\hline Type of diabetes $(1)$ & & .296 & 2.009 & .048 \\
\hline Gender & & -.127 & -1.173 & .244 \\
\hline Age & & -.273 & -1.835 & .070 \\
\hline Step $2 F(7)=23.810, p<.001$ & .650 & & & \\
\hline Type of diabetes $(1)$ & & .160 & 1.757 & .083 \\
\hline Gender & & .097 & 1.408 & .163 \\
\hline Age & & -.176 & -1.902 & .061 \\
\hline Emotional attitude & & .049 & 0.665 & .508 \\
\hline Cognitive attitude & & -.002 & -.030 & .977 \\
\hline Perceived behavioural control & & .468 & 6.176 & .001 \\
\hline Subjective norm & & .490 & 6.643 & .001 \\
\hline Step 3 F(8)=2.148, $p<.001$ & .652 & & & \\
\hline Type of diabetes $(1)$ & & .152 & 1.677 & .098 \\
\hline Gender & & .109 & 1.578 & .119 \\
\hline Age & & -.156 & -1.666 & .100 \\
\hline Emotional attitude & & .043 & 0.596 & .553 \\
\hline Cognitive attitude & & -.004 & -0.048 & .962 \\
\hline Perceived behavioural control & & .424 & 5.039 & .001 \\
\hline Subjective norm & .494 & 6.710 & .001 \\
\hline Past PA & & .094 & 1.219 & .226 \\
\hline
\end{tabular}

Table 3. Multiple hierarchical regression analyses predicting intention to exercise from sociodemographic, clinical, theory of planned behaviour variables and past physical activity behaviour and subjective norm added $19 \%$ to the variance of intentions. Altogether TPB variables accounted for $62.8 \%$ of variance of intentions. While emotional and cognitive attitudes were not related to intentions to exercise $(p>.05)$. When past PA behaviour was added in Step 3, PBC and subjective norms remained significant. Yet, past behaviour was not related to intentions $(p>.05)$.

\section{DISCUSSION}

The current study investigated the determinants of regular physical activity intentions among individuals with Type 1 and Type 2 diabetes within the framework of theory of planned behaviour. To our knowledge, this is the first study examining the unique impact of affective and cognitive attitudes separately on intentions to exercise.

Regular physical activity is considered as one of the cornerstones for managing diabetes. Results of our study support the statement that many diabetes patients fail to comply with the ADA recommendations of physical activity to be active at least 150 minutes a week only half of the sample reported daily physical activity (Nelson et al., 2002). 
It was hypothesized that perceived behavioural control would be the strongest predictor of intentions. Results of multiple hierarchical regression analyses indicated that $\mathrm{PBC}$ was really a significant predictor of intentions to exercise controlling for the type of diabetes, gender and age of patients. This shows that perception of personal ability to control behaviour matters in forming plans to perform that behaviour. This emphasizes the significance of autonomous aspects in initiating and/or maintaining health-related behaviour. Result is in line with many other studies in general population (Muzaffar, Chapman-Novakofski, Castelli, \& Scherer, 2014; Sniehotta, Scholz, \& Schwarzer, 2005), population having illness other than diabetes (McGuckin, Prentice, McLaughlin, \& Harkin, 2012) and among diabetes patients (Blue, 2007; Boudreau \& Godin, 2014; Boudreau \& Godin, 2009; Davies, 2008; Plotnikoff, Lippke, Courneya, Birkett, \& Sigal, 2010). In the study of Boudreau and Godin (2009), PBC remained significant in patients with diabetes even when anticipated affect, moral norms, descriptive norm were entered into regression analysis. Yet, there is also contradictory evidence which did not show significant effect of $\mathrm{PBC}$ on intentions. Omondi et al. (2010) found that with regards to intentions for physical activity, perceived behavioural control was not the significant predictor indicating that the patients in their study had poor control over physical activity behaviour.

Nevertheless, in the current study subjective norms which reflect social pressure and encouragement were even stronger predictors of intentions to exercise. Some studies are in line with this result and their authors propose that it implies that norms including the perceived expectations of significant others (e.g. family, doctors, nurses or work colleagues) with regard to physical activity behaviour have significant influence on intention to engage in exercise (Blue, 2007; Omondi et al., 2010). However, in the study of Boudreau and Godin (2009), subjective norms were significant in predicting intentions only when attitudes and PBC were included in regression, but when anticipated effect, moral norms, descriptive norms were entered into regression analysis, subjective norms did not reach the significance level. Other authors explain that failure of subjective norms to predict intentions may partly be attributable to a poor measurement and the need for more accurate measure of the subjective norms component (Armitage \& Conner, 2001). Yet, there is also suggestion that the exercise intention may relate to the patients with diabetes believing that exercise was their own responsibility, which shows that autonomous decisions are more important than being under control (Davies, 2008). Following the previous premises and regarding the results of the current study it could be concluded that social pressure aspect was well captured in the questionnaire in the present study and for diabetic patients in our sample both autonomous (PBC) and controlling (subjective norms) psychosocial aspects were almost equally important for intending to engage in PA.

Moreover, $\mathrm{PBC}$ and subjective norms were the only predictors and accounted for a significant amount of variance $(62.8 \%)$ of intentions. The results match the findings of McGuckin et al. (2012) in mixed population of patients with chronic illness and Blue's (2007) study on adults at risk for diabetes, where these factors also were the sole predictors. This suggests that planning intervention programs for increasing PA of people with diabetes encouraging $\mathrm{PBC}$ and taking into account the empowering role of significant others is crucial.

No study to date has adopted a model where attitudes were distinguished between affective and cognitive in diabetic population. Although it is important as PA in case of diabetes is not only enjoyable activity but a part of the treatment. It was expected that affective attitudes in the present study along with the PBC would be the salient predictors of intentions. However, neither affective nor cognitive attitudes were prominent for planning future physical activity behaviour. Meanwhile studies in general samples highlight the importance of affective attitudes over cognitive (Lawton et al., 2007). Though, mixed attitudes in many other studies were among the most salient predictors of intentions to exercise (Boudreau \& Godin, 2014; Boudreau \& Godin, 2009; Davies, 2008; Omondi et al., 2010; Plotnikoff et al., 2010; Plotnikoff et al., 2008). The authors explain that intervention programs should focus on positive attitudes towards PA highlighting the benefits (cognitive attitudes) and enjoyment (affective attitudes) aspects of exercising (Plotnikoff et al., 2008). Other authors argue that the role of attitudes in initiating and maintaining behaviour may be limited and despite positive beliefs in relation to performing behaviour, do not relate to any greater intentions to behave in a certain way compared to those with less positive beliefs (McGuckin et al., 2012). This is especially true in chronically ill population when behaviour as a rule is prescribed by physician and the personal attitudes towards 
health-behaviour become less important than the attitudes of those significant others as physicians. This explains our results that subjective norms were salient predictors while attitudes failed to predict intentions.

Finally, the importance of past behaviour was also tested as other studies suggest that it may be important in forming intentions for future behaviour (Boudreau \& Godin, 2014) because it may act as positive or negative experience. In the current study correlational analysis revealed only weak correlation with intentions, yet regression analysis did not indicate any significant impact on intentions when other TPB variables were included into the regression. It was also hypothesized that past behaviour would be related to both affective and cognitive attitudes as supposed to be the basis for them, but correlations were although significant, yet weak.

The results should be interpreted in the context of study limitations. The study sample was small and cannot represent all of the diabetes population in Lithuania. Study design was cross-sectional and limited further and deeper analysis on how intentions are converted into physical activity behaviour.

\section{CONCLUSION}

Perceived behavioural control and subjective norms were two significant psychosocial determinants within the theory of planned behaviour which explain intentions to engage in physical activity among people with diabetes. So, enhancing self-efficacy and ability to control the disease as well as strengthening positive relationships of patients with significant others (e.g. members of the team involved in the treatment) whose attitudes then would be regarded, should be considered developing interventions aimed at increasing the motivation of patients with diabetes to regularly practice physical activities.

\section{REFERENCES}

Ajzen, I. (2006). Designing a TPB questionnaire. Retrieved from http://www.unibielefeld.de/ikg/zick/ ajzen $\% 20$ construction $\% 20 \mathrm{a} \% 20$ tpb $\% 20$ questionnaire. pdf

Ajzen, I. (1991). The theory of planned behavior. Organizational Behavior and Human Decision Processes, 50(2), 179-211. doi:10.1016/07495978(91)90020-t

Armitage, C. J., \& Conner, M. (2001). Efficacy of the Theory of Planned Behaviour: A meta-analytic review. British Journal of Social Psychology, 40(4), 471-499. doi:10.1348/014466601164939

Blue, C. L. (2007). Does the theory of planned behavior identify diabetes-related cognitions for intention to be physically active and eat a healthy diet? Public Health Nursing, 24(2), 141-150.

Boudreau, F., \& Godin, G. (2014). Participation in regular leisure-time physical activity among individuals with Type 2 diabetes not meeting Canadian guidelines: The influence of intention, perceived behavioral control, and moral norm. International Journal of Behavioral Medicine, 21(6). 918-926. doi:10.1007/s12529-0139380-4

Boudreau, F., \& Godin, G. (2009). Understanding physical activity intentions among French Canadians with type 2 diabetes: An extension of Ajzen's theory of planned behaviour. International Journal of Behavioral Nutrition and Physical Activity, 6(1), 35. Retrieved from http://dx.doi.org/10.1186/1479-5868-6-35

Carter-Parker, K., Edwards, K. A., \& McClearyJones, V. (2012). Correlates of physical activity and the
Theory of Planned Behavior between African American women who are physically active and those who are not. ABNF Journal, 23(3), 51-58.

Chimen, M., Kennedy, A., Nirantharakumar, K., Pang, T. T., Andrews, R., \& Narendran, P. (2011). What are the health benefits of physical activity in type 1 diabetes mellitus? A literature review. Diabetologia, 55(3), 542-551. doi:10.1007/s00125-011-2403-2

Conner, M. (2013). Health cognitions, effect and health behaviors. The European Health Psychologist, 15(2), 33-39.

Davies, C. (2008). The relationship between the theory of planned behaviour, past exercise behaviour and intention in individuals diagnosed with Type 2 Diabetes. Studies in Learning, Evaluation, Innovation and Development, 5(2), 25-32.

Hagger, Mm. S., Chatzisarantis, N. L. D., Barkoukis, V., Wang, J. C. K., Hein, V., Pihu, M., ... Karsai, I. (2007). Cross-cultural generalizability of the theory of planned behavior among young people in a physical activity context. Journal of Sport and Exercise Psychology, 29(1), 1-20.

Hayashino, Y., Jackson, J. L., Fukumori, N., Nakamura, F., \& Fukuhara, S. (2012). Effects of supervised exercise on lipid profiles and blood pressure control in people with type 2 diabetes mellitus: A metaanalysis of randomized controlled trials. Diabetes Research and Clinical Practice, 98(3), 349-360. doi:10.1016/j.diabres.2012.10.004

Kraft, P., Rise, J., Sutton, S., \& Røysamb, E. (2005). Perceived difficulty in the theory of planned behaviour: 
Perceived behavioural control or affective attitude? British Journal of Social Psychology, 44(3), 479-496. doi:10.1348/014466604x17533

Lawton, R., Conner, M., \& Parker, D. (2007). Beyond cognition: Predicting health risk behaviors from instrumental and affective beliefs. Health Psychology, 26(3), 259-267. doi:10.1037/0278-6133.26.3.259

Martin, J. J., Oliver, K., \& McCaughtry, N. (2007). The theory of planned behavior: Predicting physical activity in Mexican American children. Journal of Sport and Exercise Psychology, 29(2), 225-238.

McGuckin, C., Prentice, G. R., McLaughlin, C. G., \& Harkin, E. (2012). Prediction of self-monitoring compliance: Application of the theory of planned behaviour to chronic illness sufferers. Psychology, Health \& Medicine, 17(4), 478-487. doi:10.1080/1354 8506.2011 .630399

Muzaffar, H., Chapman-Novakofski, K., Castelli, D. M., \& Scherer, J. A. (2014). The HOT (Healthy Outcome for Teens) project. Using a web-based medium to influence attitude, subjective norm, perceived behavioral control and intention for obesity and type 2 diabetes prevention. Appetite, 72, 82-89. doi:10.1016/j.appet.2013.09.024

Nelson, K. M., Reiber, G., \& Boyko, E. J. (2002). Diet and exercise among adults with Type 2 diabetes. Diabetes Care, 25, 1722-1728.

Omondi, D. O.,Walingo, M. K., Mbagaya, G. M., \& Othuon, L. O. A. (2010). Understanding physical activity behavior of Type 2 diabetics using the Theory of Planned Behavior and Structural Equation Modeling. World Academy of Science, Engineering and Technology, 4(03), 28.

Patrick, H., \& Williams, G. C. (2012). Selfdetermination theory: Its application to health behavior and complementarity with motivational interviewing. International Journal of Behavioral Nutrition and Physical Activity, 9(1), 18. doi:10.1186/1479-5868-9-18
Plotnikoff, R. C., Courneya, K. S., Trinh, L., Karunamuni, N., \& Sigal, R. J. (2008). Aerobic physical activity and resistance training: An application of the theory of planned behavior among adults with type 2 diabetes in a random, national sample of Canadians. International Journal of Behavioral Nutrition and Physical Activity, 5(1), 61. doi:10.1186/1479-5868-5-61 Plotnikoff, R. C., Lippke, S., Courneya, K., Birkett, N., \& Sigal, R. (2010). Physical activity and diabetes: An application of the theory of planned behaviour to explain physical activity for Type 1 and Type 2 diabetes in an adult population sample. Psychology \& Health, 25(1), 7-23. doi:10.1080/08870440802160984

Plotnikoff, R. C., Lubans, D. R., Costigan, S. A., Trinh, L., Spence, J. C., Downs, S., \& McCargar, L. (2011). A test of the theory of planned behavior to explain physical activity in a large population sample of adolescents from Alberta, Canada. Journal of Adolescent Health, 49(5), 547-549. doi:10.1016/j.jadohealth.2011.03.006

Resnick, H. E., Foster, G. L., Bardsley, J., Ratner, R. E. (2006). Achievement of American Diabetes Association clinical practice recommendations among U.S. adults with diabetes, 1999-2002. Diabetes Care, 29, 531-537. Sniehotta, F. F., Scholz, U., \& Schwarzer, R. (2005). Bridging the intention-behaviour gap: Planning, self-efficacy, and action control in the adoption and maintenance of physical exercise. Psychology \& Health, 20(2), 143-160. doi:10.1080/08870440512331317670

Standards of Medical Care in Diabetes-2011. (2010). Diabetes Care, 34(Suppl. 1), S11-S61. doi:10.2337/ dc11-s011

Standards of Medical Care in Diabetes-2012. (2011). Diabetes Care, 35(Suppl. 1), S11-S63. doi:10.2337/ dc12-s011

Toobert, D. J., Hampson, S. E., \& Glasgow, R. E. (2000). The summary of diabetes self-care activities measure: Results from 7 studies and a revised scale. Diabetes Care, 23(7), 943-950. doi:10.2337/diacare.23.7.943 